\title{
Commercial Production of Multi-Layer Graphene Nanomaterials
}

\section{Sharma KR*}

Texas Southern University, Houston, TX, USA

A couple of months ago, my services as council member of Gerson Lehrman Group were requested by a client via the internet platform at a rate of $\$ 400$ per hour. The client who remained anonymous consulted with me for 43 minutes about emerging graphene markets. He and another executive wanted to know where the challenges that lie ahead were in (i) Were they in finding new multi-layer graphene markets or (ii) Were the challenges lie in the areas of scale-up and production of multi-layer and single layer graphene.

Graphenenano makes batteries and other energy storage devices using graphene. These have higher capacity compared with lithium ion and lithium sulfur batteries. Preito battery was announced at a ACS national meeting. The battery recharge time was cut down to minutes from hours. The energy density of batteries made by Graphenenano was $1000 \mathrm{Wh} / \mathrm{kg}$ compared with $180 \mathrm{Wh} / \mathrm{kg}$ for the lithium ion batteries. The production cost for multi-layer graphene is expected to drop down to $\$ 58 / \mathrm{kg}$ in 10 years. Current price for SG is $\$ 60$ on copper substrates for a sq. inch and $\$ 100 / \mathrm{kg}$ for multi-layer graphene.

Graphenes are used in conductive inks, lubricants, anti-corrosion coating and energy storage materials. Research is underway to confirm its use in condenser microphones, loudspeakers, nanocomposites, AR coatings in solar cells, lighter and stronger tennis rackes, photonics, supercapacitors, catalyst with higher surface area, rocket nozzles, electromagnetic shielding, and flexible electronics etc. National Graphene institute in UK is a $\$ 90$ million hub with 250 researchers from 50 partner companies working on graphene. By 2018 there is going to commisioned building that cost $\$ 85$ million at NGI. Scale-up and new business development are important considerations here. Market size projections have been put forword by lux report and IDTechex 300 tons/yr of graphene line was commisioned in August 2013 by Ningbo Morsh Technology.

EU is spending 1 billion euros in the next 10 years in order to find new markets for graphene. China with $47 \%$ of recent graphene patents is building infrastructure that can be used to reach target world production of 3800 metric tons/yr of graphene. I suggested during the meeting, building on the Raman characterization, hrTEM imaging, XRD peak broadening and confirmation of SG and multi-layer graphene and develop an on-line imaging instrument. Raleigh criterion puts the cutoff at $200 \mathrm{~nm}$ for resolution. Optical imaging can be used to distinguish the materials based on the number of layers present.

SG is pink in color. This is so upto 10 layers. 30-40 layers are found to be blue. Yellow color would mean 100 layers. Graphite powder is black. 60-80 layers can be expected to be green.

The client wanted a top-down approach. Depositional, lithorgraphic and epitaxial methods can be used. A proactive solution for agglomeration seen during production of CNTs (Molecular Rebar, Austin TX does things like this) can be the addition of surfactant to the mixing of graphite powder with solvents, water under shear. Energy is needed in order to create larger surface area on account of miniaturization. Exponential energy draw with reduction in size can be seen from computer simulations.

IMB, Samsung and Xerox are leading players in graphene story. Trinity college, Dublin has lincensed the graphene production to Korean institute and Thomas Swan. Thomas Swan family nearly 100 years ago invested in tar road. Now they are investing in graphene. They produce graphene at a rate of 15 metric tons/yr. The client wanted to know what makes the nanocomposite with graphene dispersion tougher. Ductile fracture due to shear yielding may be the reason. Crazing is seen with higher sized dispersions. I pointed out to them the lower cost of synthetic diamond films. Graphene can be seen in puckered, arm chair and chiral morphologies. GO, graphene oxide, GNP graphene nanoplatelets, graphene nanoribbons can be prepared. Exfoliation using NMP is a viable method. I have used NMP to extract coal.

The liquid dispersion color changes from brown to black in the Hummers procedure. The client was asking about the color change in solid or liquid. The executive commented on the product uniformity.
*Corresponding author: Kal Renganathan Sharma, Adjunct Professor, Texas Southern University, Houston, TX, USA, Tel: 281-256-2976; E-mail: jyoti_kalpika@yahoo.com

Received September 12, 2016; Accepted October 20, 2016; Published October 28, 2016

Citation: Sharma KR (2016) Commercial Production of Multi-Layer Graphene Nanomaterials. J Laser Opt Photonics 3: 135. doi: 10.4172/2469-410X.1000135

Copyright: () 2016 Sharma KR. This is an open-access article distributed under the terms of the Creative Commons Attribution License, which permits unrestricted use, distribution, and reproduction in any medium, provided the original author and source are credited. 